\title{
Normal Diaphragm Measurements in the Saudi Population Using Posteroanterior Chest Radiograph
}

\author{
S. Alghamdi ${ }^{*}, \mathrm{PhD} ; \mathrm{L}$. Bushara ${ }^{1}, \mathrm{PhD} ; \mathrm{D}$. Bilal ${ }^{1}, \mathrm{PhD}$; Hind Alghamdi ${ }^{2}, \mathrm{MD}$; \\ Ikhlas Abdulaziz ${ }^{1}$, PhD; R. Aljondi ${ }^{1}, \mathrm{PhD} ; \mathrm{S}$. Aldahery ${ }^{1}, \mathrm{PhD} ;$ A Tajaldeen $^{3}$, PhD \\ ${ }^{I}$ Department of Applied Radiologic Technology, College of Applied Medical Sciences, University of \\ Jeddah, Jeddah, Saudi Arabia \\ ${ }^{2}$ Radiology Department, King Fahad General Hospital, Jeddah, Saudi Arabia \\ ${ }^{3}$ Radiological Science Department, College of Applied Medical Science, Imam Abdulrahman Bin Faisal \\ University, Dammam, Saudi Arabia
}

\begin{abstract}
The aim of this study was to establish normal measurements of the hemidiaphragm widths and heights in the Saudi population by a posteroanterior (PA) chest X-ray in the Mecca Region.

Methods and Results: The data were collected prospectively at King Abdulaziz Hospital in Saudi Arabia, Jeddah, between March and April 2021, using a computed radiography imaging unit. A total of 45 patients $(51.1 \%$ men and $48.9 \%$ women; the age range between 15 and 79 years) were included in the study. Measurements were obtained on an ideal PA chest radiograph by measuring the distance from the highest points of the right hemidiaphragm and left hemidiaphragm. The width from the right and left costophrenic angle was also measured as an ended point. The total diaphragm width (DW) was $278.32 \pm 24.83 \mathrm{~mm}$, the total right diaphragmatic dome height (RDDH) $-51.30 \pm 10.58 \mathrm{~mm}$, and left diaphragmatic dome height (LDDH) $-38.40 \pm 9.21 \mathrm{~mm}$.

The DW was greater in men than in women: $291.74 \pm 20.4 \mathrm{~mm}$ and $264.28 \pm 21.2 \mathrm{~mm}$, respectively. RDDH and LDDH were also greater in men than in women: $55.4 \pm 6.77 \mathrm{~mm}$ and $47.005 \pm 12.19 \mathrm{~mm}$, and $43.29 \pm 6.65 \mathrm{~mm}$ and $33.28 \pm 8.83 \mathrm{~mm}$, respectively

Conclusion: Computed radiography was useful in measuring the diaphragm because measurement points can be identified accurately and easily due to the availability of the processing system functions such as the ability to manipulate the image resolution, image contrast, and magnification.(International Journal of Biomedicine. 2021;11(2):206-211.)
\end{abstract}

Key Words: diaphragm • posteroanterior chest X-ray • Saudi population

For citation: Alghamdi S, Bushara L, Bilal D, Alghamdi H, Abdulaziz I, Aljondi R, Aldahery S, Tajaldeen A. Normal Diaphragm Measurements in the Saudi Population Using Posteroanterior Chest Radiograph. International Journal of Biomedicine. 2021;11(2):206-211. doi:10.21103/Article11(2)_OA14

\section{Abbreviations}

CT, computed tomography; DW, diaphragm width; LDDH, left diaphragmatic dome height; LHD, left hemidiaphragm; PA, posteroanterior; RDDH, right diaphragmatic dome height; RHD, right hemidiaphragm.

\section{Introduction}

The diaphragm is a thin layer of muscle that has the main function of controling the process of normal breathing, also acting as a physical barrier separating the thorax from the abdomen. ${ }^{(1,2)}$ Often, it can be a cause of dyspnea due to dysfunction, which can be either intrinsic or extrinsic. ${ }^{(3)}$ It has several links to the thoracic wall that can be seen with radiological imaging, such as $\mathrm{CT}$, which is an important point of reference for image interpretation. ${ }^{(4)}$ Evaluation of chest $\mathrm{X}$-rays may seem simple, but it is actually a complex task and requires observation of the diaphragm's location and shape, which are commonly used to determine whether the lungs are underinflated or hyperinflated. ${ }^{(5)}$ Therefore, an understanding of the normal anatomy of the chest is essential for an accurate diagnosis of the diaphragm. ${ }^{(6)}$ 
The crus of the diaphragm extends to the lumbar vertebral bodies and disks beneath the diaphragm, attaches the diaphragm to the lumbar vertebral bodies and disks, and is joined by the median arcuate ligament..$^{(1)}$ The median arcuate ligament extends as fibrous bands between the first and second lumbar vertebral bodies and the first lumbar transverse process over the anterior psoas muscle as fibrous bands, ${ }^{(7)}$ while the lateral arcuate ligament consists of fascial bands covering the quadratus lumborum muscle and extending from the twelfth thoracic transverse process to the middle portion of the twelfth thoracic ribs. ${ }^{(1)}$ These ligaments are better depicted with CT imaging. ${ }^{(8)}$ While the use of CT has increased considerably in recent decades, a chest X-ray is the most commonly performed imaging test. ${ }^{(9)}$

During inhalation, the diaphragm contracts and moves in the inferior direction, thereby increasing the thoracic cavity volume by drawing air into the lungs. ${ }^{(2)}$ The RHD appears to be marginally higher than the LHD. Additionally, the diaphragm's anterior and medial portions are regularly higher than the posterior and lateral portions. ${ }^{(1)}$ This finding is relatively common; therefore, during interpretation, radiologists should be familiar with variants of the diaphragm to avoid unnecessary concern and further evaluation. Accordingly, an elevated hemidiaphragm on a chest X-ray can occur for a number of reasons. It can be from diminished lung volume, phrenic nerve paralysis, eventration of the diaphragm, subphrenic abscess, hepatomegaly, or splenomegaly. ${ }^{(10)}$

An elevated diaphragm might be difficult for clinicians to identify due to their relative rareness. ${ }^{(1)}$ As the elevated diaphragm is usually undiagnosed during clinical examination, it should not be neglected, since this can adversely affect the quality of life, and can also be a predictor of the seriousness of pathology. ${ }^{(12)} \mathrm{A}$ chest X-ray is the most frequent radiologic examination used to evaluate the diaphragm because it is very simple and accessible. ${ }^{(5)}$

Knowledge of the normal height of RHD and LHD can be helpful in diagnosing some chest diseases and some sub-diaphragmatic organ diseases, ${ }^{(13)}$ as knowledge of the normal height of the diaphragm could help the radiologists to indicate other radiologic examinations, such as abdominal ultrasound, CT chest or cervical MRI (if it was found that there is diaphragmatic elevation), in order to find the cause of this disorder. ${ }^{(14)}$ Since the literature includes very little data on determining the normal variation in diaphragm position and shape,$^{(15)}$ the aim of this study was to establish normal measurements of the hemidiaphragm widths and heights in the Saudi population by a PA chest X-ray in the Mecca Region.

\section{Materials and Methods}

The data were collected prospectively at King Abdulaziz Hospital in Saudi Arabia, Jeddah, between mid-March and April 2021, using a computed radiography imaging unit. A total of 45 patients $(51.1 \%$ men and $48.9 \%$ women; the age range between 15 and 79 years) were included in the study. PA chest X-ray was performed by using an X-ray machine (Shimadzu, Japan. Focal spot: Small (0.6) mm / Large (1.2) mm; Maximum kV: 150 kVp; Maximum mA: 500mA; Year of
Installation: 2011.3-1-3). Images were processed with a Fuji FCR CAPSULA XLII Computed Radiography System.

All participants were diagnosed with a normal chest $\mathrm{X}$-ray. Excluded were patients with severe pathological conditions, such as pleural effusion, collagen vascular disease, pulmonary hypertension, cardiomegaly, ascites, liver cirrhosis, hepatomegaly, or splenomegaly.

Image acquisition

Measurements were obtained on an ideal PA chest radiograph by measuring the distance from the highest points of the RHD and LHD. The width from the right and left costophrenic angle was also measured as an ended point. The $P A$ view is a standard view for a chest $\mathrm{X}$-ray. For all adults. patients were in an upright position facing the cassette with the patient's chin resting at the middle of the top of the Bucky. The feet were placed slightly apart to keep the patient steady. The median sagittal plane was adjusted to the middle of the cassette. The shoulders were rotated forward and in contact with the cassette by placing the dorsal aspect of the hands behind and below the hips, with the elbows brought forward or allowing the arms to encircle the Bucky (Figure 1).



Fig. 1. A PA Chest X-ray. Recommended patient position. ${ }^{(19)}$

For an ideal PA chest X-ray, patients were asked to take a deep breath and hold it, and the image was acquired at inspiration. The exposure factor was $110 \mathrm{kVp}$ and $8 \mathrm{mAs}$. A PA chest X-ray image of a middle-aged female is presented in Figure 2. The detail of signs of a good quality PA image and anatomy is included in the quality of the image and the radiological anatomy part.

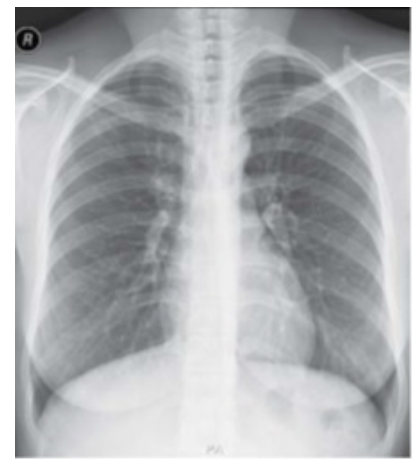

Fig. 2. PA CXR image showing a good quality image, with equidistant clavicles at the level of the T4 thoracic vertebra, all the necessary areas of the chest included. The anterior 7 ribs and the posterior 10 ribs are visible above the diaphragm showing good inspiration. There is a subtle abnormal finding - RT upper. 


\section{Image analysis}

Two certified technologists, bachelor's degree (BSc) in diagnostic imaging and $\mathrm{PhD}$ in cross sectional imaging, independently reviewed the chest X-ray images for diaphragm measurement for all patients on two separate days (at least two weeks apart).. Images were initially reviewed to be excluded for the absence of severe pathology. During a separate subsequent session, images were measured as the following (Figure 3):

- A vertical line was drawn at the maximum height of each hemidiaphragm.

- A straight parallel line was drawn at the maximum height of each hemidiaphragm, to measure the distance between both lines.

- A straight line was drawn between two costophrenic angles to measure the width.

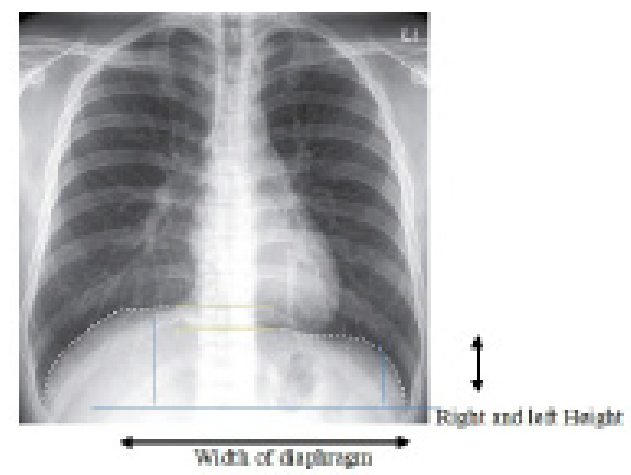

Fig. 3. Diaphragm measurement of the RHD and LHD (Study Protocol).

Statistical analysis was performed using the IBM SPSS Statistics for Windows, Version 22.0. Armonk, NY: IBM Corp.). The normality of distribution of continuous variables was tested by the Kolmogorov-Smirnov test with the Lilliefors correction and Shapiro-Wilk test. Baseline characteristics were summarized as frequencies and percentages for categorical variables and as mean \pm standard deviation (SD) for continuous variables. Means of 2 continuous normally distributed variables were compared by independent samples Student's $t$ test. Differences of continuous variables departing from the normal distribution, even after transformation, were tested by the Mann-Whitney U-test. The frequencies of categorical variables were compared using Pearson's chi-squared test or Fisher's exact test, when appropriate.A probability value of $P<0.05$ was considered statistically significant.

\section{Results}

The following figures and tables presented the data obtained from 45 normal subjects after measuring the width and height of the RHD and LHD. The other variables taken were age and gender. Correlations were applied by presenting a trend line and resultant equations in the graphs; this was done for males (51.1\% of the sample) and the females $(48.9 \%$ of the sample), as well as the total sample values.

Figure 4 presents the frequency distribution of age/years for the age groups (15-25), (26-36), (37-47), (48-58), (59-69),
(70-79) by the valid percentage $28.9 \%, 26.7 \%, 26.7 \%, 8.9 \%$, $6.7 \%, 2.2 \%$, respectively. Figure 5 presents the frequency distribution of gender by the valid percentage of $51.1 \%$ for males and $48.9 \%$ for females.
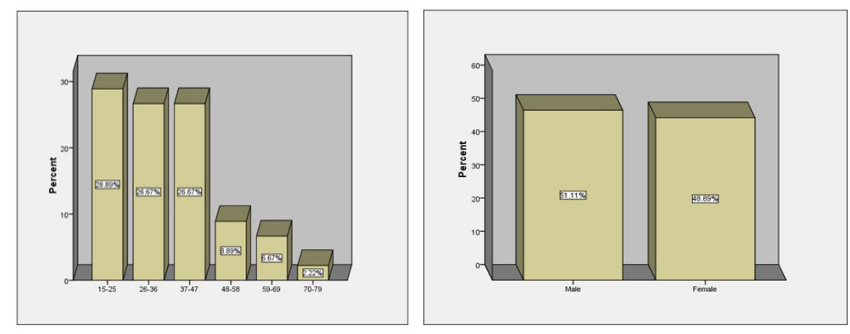

Fig. 4. The frequency distribution Fig. 5. The frequency distribution of agelyears for the age groups. of gender

Table 1 presents the total sample means and standard deviations of the variables. The sample age was $36.29 \pm 15.18$ years. The total DW was $278.32 \pm 24.83 \mathrm{~mm}$, the total RDDH $-51.30 \pm 10.58 \mathrm{~mm}$, and LDDH - 38.40 $\pm 9.21 \mathrm{~mm}$. Table 2 compares the values of DW, LDDH, and RDDH in different age groups. The DW and RDDH were greater in age group 70-79 years, and LDDH was greater in age group 26-36 years.

Table 1.

\section{Descriptive statistics for age, $D W, R D D H$ and $L D D H$}

\begin{tabular}{|c|c|c|c|c|c|}
\hline Variable & N & Minimum & Maximum & Mean & SD \\
\hline Age & 45 & 15 & 79 & 36.29 & 15.18 \\
\hline DW & 45 & 212.0 & 338.5 & 278.32 & 24.83 \\
\hline RDDH & 45 & 29.0 & 69.0 & 51.30 & 10.58 \\
\hline LDDH & 45 & 20.0 & 56.6 & 38.40 & 9.21 \\
\hline
\end{tabular}

Table 2.

The values of $D W, L D D H$, and RDDH in different age groups

\begin{tabular}{|c|c|c|c|c|}
\hline Agelyears & & DW & $\mathrm{RDDH}$ & LDDH \\
\hline \multirow{2}{*}{$15-25$} & Mean & 275.85 & 50.52 & 39.62 \\
\hline & Std. Deviation & 22.53 & 10.57 & 8.01 \\
\hline \multirow{2}{*}{$26-36$} & Mean & 275.50 & 53.20 & 40.88 \\
\hline & Std. Deviation & 28.36 & 8.70 & 10.63 \\
\hline \multirow{2}{*}{$37-47$} & Mean & 274.66 & 50.16 & 38.61 \\
\hline & Std. Deviation & 22.60 & 11.19 & 8.62 \\
\hline \multirow{2}{*}{$48-58$} & Mean & 302.80 & 51.32 & 34.00 \\
\hline & Std. Deviation & 28.15 & 16.29 & 10.58 \\
\hline \multirow{2}{*}{$59-69$} & Mean & 273.83 & 47.23 & 29.90 \\
\hline & Std. Deviation & 19.50 & 12.12 & 8.75 \\
\hline $70-79$ & Mean & 303.60 & 64.20 & 33.20 \\
\hline \multirow{2}{*}{ Total } & Mean & 278.32 & 51.30 & 38.40 \\
\hline & Std. Deviation & 24.83 & 10.58 & 9.21 \\
\hline $\mathrm{P}$-value & & 0.361 & 0.79 & 0.445 \\
\hline
\end{tabular}


Table 3 showed a significant correlation between DW and RDDH, LDDH in different ages. The DW was greater in men than in women: $291.74 \pm 20.4 \mathrm{~mm}$ and $264.28 \pm 21.2 \mathrm{~mm}$, respectively (Table 4). RDDH and LDDH were also greater in men than in women: $55.4 \pm 6.77 \mathrm{~mm}$ and $47.005 \pm 12.19 \mathrm{~mm}$, and $43.29 \pm 6.65 \mathrm{~mm}$ and $33.28 \pm 8.83$, respectively (Table 4).

\section{Table 3.}

Correlations between $D W$ and $R D D H, L D D H$ in different ages.

\begin{tabular}{|c|c|c|c|c|c|}
\hline & & Age & DW & RDDH & LDDH \\
\hline \multirow{3}{*}{ Age } & Pearson Correlation & 1 & .160 & $-.007-$ & $-.278-$ \\
\hline & Sig. (2-tailed) & & .295 & .961 & .065 \\
\hline & $\mathrm{N}$ & 45 & 45 & 45 & 45 \\
\hline \multirow{3}{*}{ DW } & Pearson Correlation & .160 & 1 & $.528^{* *}$ & $.377^{*}$ \\
\hline & Sig. (2-tailed) & .295 & & .000 & .011 \\
\hline & $\mathrm{N}$ & 45 & 45 & 45 & 45 \\
\hline \multirow{3}{*}{ RDDH } & Pearson Correlation & $-.007-$ & $.528^{* *}$ & 1 & $.393^{* *}$ \\
\hline & Sig. (2-tailed) & .961 & .000 & & .007 \\
\hline & $\mathrm{N}$ & 45 & 45 & 45 & 45 \\
\hline \multirow{3}{*}{ LDDH } & Pearson Correlation & $-.278-$ & $.377^{*}$ & $.393^{* *}$ & 1 \\
\hline & Sig. (2-tailed) & .065 & .011 & .007 & \\
\hline & $\mathrm{N}$ & 45 & 45 & 45 & 45 \\
\hline \multicolumn{6}{|c|}{ **. Correlation is significant at the 0.01 level (2-tailed). } \\
\hline
\end{tabular}

Table 4.

Independent t test to compare $\mathrm{DW}, \mathrm{RDDH}$ and $\mathrm{LDDH}$ in different gender

\begin{tabular}{|c|l|l|l|l|c|}
\hline \multirow{2}{*}{ DW } & Gender & N & Mean & Std. Deviation & Std. Error Mean \\
& Fale & 23 & 291.74 & 20.4029 & 4.2543 \\
\hline \multirow{2}{*}{ RDDH } & Male & 23 & 55.400 & 6.7725 & 1.4122 \\
& Female & 22 & 264.28 & 21.2577 & 4.5322 \\
\hline \multirow{2}{*}{ LDDH } & Male & 23 & 47.005 & 12.1929 & 2.5995 \\
& Female & 22 & 33.286 & 8.8324 & 1.8831 \\
\multirow{2}{*}{ Age } & Male & 23 & 33.87 & 15.212 & 3.172 \\
& Female & 22 & 38.82 & 15.067 & 3.212 \\
\hline
\end{tabular}

Figure 6 showed the relationship between age and RDDH/LDDH. Figure 7 showed the relationship between age and diaphragm width.

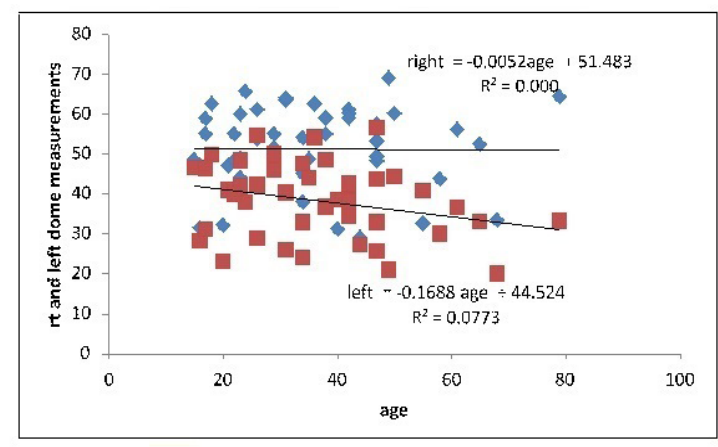

Fig. 6. Scatter plot. The relationship between age and $R D D H, L D D H$

$$
\begin{array}{cc}
R D D H=-0.0052 \text { age }+51.483 & R^{2}=0.000 \\
L D D H=-0.1688 \text { age }+44.524 & R^{2}=0.0773
\end{array}
$$



Fig. 7. Scatter plot. The relationship between age and $D W$.

$Y=0.2613 x+268.84, R^{2}=0.0255$

\section{Discussion}

On chest $\mathrm{X}$-rays, the position and shape of the diaphragm are commonly used as indicators of normal or abnormal lung volume. ${ }^{(15)}$ However, there is a lack of research that evaluates the normal diaphragm position and shape on an X-ray, based on the measurements and documentation of pulmonary function, without taking into account the observed variability, which includes measurements performed on an ideal PA chest X-ray, and measurement points clearly identified. ${ }^{(10,15,16)}$ This study showed that measurements of the RHD and LHD based on the height and width are slightly sensitive, even when excluding patients with severe clinical pathology.

It has been documented that the use of a chest X-ray as an imaging test is beneficial for chest diagnosis, and in most cases, the diagnosis of hemidiaphragm paralysis can be diagnosed radiologically. ${ }^{(16)}$ Nason et al. ${ }^{(1)}$ identified that the RHD is normally slightly higher than the LHD. Some previous studies published similar findings. H.A.A. Salih ${ }^{(13)}$ obtained 100 cases to measure the height difference between RHD and LHD on PA chest digital radiographs obtained from Sudanese patients with normal chest and abdomen. The authors found 
that the RHD is normally higher than LHD in $98 \%$ of patients in the range of $1-3 \mathrm{~cm}$ with the age ranging from $16-42$ years. In addition, Suwatanapongched et al. ${ }^{(15)}$ have prospectively determined and compared the spectrum of diaphragm position and shape on chest X-rays between non-obese and obese patients by using three methods. The first measurement was by relating each hemidiaphragm dome to the vertebral level of the thoracic spine. Secondly, a horizontal line was drawn through the midpoint of the intersecting shadows of the anterior sixth and posterior tenth ribs, on each side. The height of both right and left lungs was used as a third indicator of diaphragm position, measured from the inferior margin of the second rib to the hemidiaphragm dome. The shape of the diaphragm was also determined but only on the right side by using the radius of curvature of the RHD as an indicator. ${ }^{(15)}$ This study also found that the RHD is higher than the LHD in $93 \%$ of cases by $03-0.9 \mathrm{~cm}$, with the age ranging from $18-86$ years.

These findings support that the radiological evaluation of the diaphragm might pose a potential pitfall, as the normal height of the hemidiaphragm may considerably vary and a wide range of normal or abnormal circumstances based on easily recognized anatomic landmarks used, and analysis of factors that might contribute to this variation, such as age and weight, can provide a more reliable basis for such evaluation. To improve the diagnostic sensitivity of chest radiographs of elevated diaphragm pathologies, the $\mathrm{CT}$ is sometimes suggested as a complementary test. ${ }^{(17)}$ However, it must be taken into consideration that the radiation dose associated with a chest $\mathrm{CT}$ is much higher than a routine chest X-ray. ${ }^{(18)}$

This study found a result that is conformable with previous studies, but on the Saudi population. Although the findings showed that the RHD is higher than the LHD, we found that the RHD in the Saudi population is higher than in other populations, such as the Sudanese. ${ }^{(13)}$ It was also found that the RHD is higher in males than in females.

To the best of the researchers' knowledge, this is the first study that evaluated the height and width of hemidiaphragm on chest X-rays among the Saudi population.

The limitation of this study is that the clinical indication of the study population contains chest symptoms that were not generally considered normal. However, all patients had a normal chest X-ray and no radiographic abnormalities predicted to impact the diaphragm height and width. The Saudi population reflects patients routinely seen in a hospital-based practice. The results might not be similar in an asymptomatic, non-referred, unselected population. This study can be repeated on a larger sample in order to provide a more rigorous definition of the normal height and width of the diaphragm and identify factors that influence the variation.

\section{Conclusion}

The height of RHD and LHD, as well as DW was higher in men than in women. There is a significant correlation between hemidiaphragm height, DW and age, as they increase during the age increasing.

\section{Competing Interests} interests.

The authors declare that they have no competing

\section{References}

1. Nason LK, Walker CM, McNeeley MF, Burivong W, Fligner CL, Godwin JD. Imaging of the diaphragm: anatomy and function. Radiographics. 2012 Mar-Apr;32(2):E51-70. doi: $10.1148 / \mathrm{rg} .322115127$.

2. Kocjan J, Adamek M, Gzik-Zroska B, Czyżewski D, Rydel M. Network of breathing. Multifunctional role of the diaphragm: a review. Adv Respir Med. 2017;85(4):224-232. doi: 10.5603/ARM.2017.0037.

3. Onders RP, Elmo M, Kaplan C, Katirji B, Schilz R. Extended use of diaphragm pacing in patients with unilateral or bilateral diaphragm dysfunction: a new therapeutic option. Surgery. 2014 Oct;156(4):776-84. doi: 10.1016/j. surg.2014.07.021.

4. Iochum S, Ludig T, Walter F, Sebbag H, Grosdidier G, Blum AG. Imaging of diaphragmatic injury: a diagnostic challenge? Radiographics. 2002 Oct;22 Spec No:S103-16; discussion S116-8. doi: 10.1148/radiographics.22.suppl_1. g02oc14s103.

5. Puddy E, Hill C. Interpretation of the chest radiograph. Anaesth Crit Care Pa 2007;7:71-75.

6. Sheard S. The Chest X-ray: a Survival Guide. Clin Radiol 2009;64:1246-1247.

7. Candelaria I, Oliveira C, Donato H, et al. The diaphragm: revision of the normal anatomy, function and iconographic review of frequent pathology with CT. Eur Radiol 2014.

8. Gmachowska A, Pacho R, Anysz-Grodzicka A, Bakoń L, Gorycka M, Jakuczun W, Patkowski W. The Role of Computed Tomography in the Diagnostics of Diaphragmatic Injury After Blunt Thoraco-Abdominal Trauma. Pol J Radiol. 2016 Nov 4;81:522-528. doi: 10.12659/PJR.897866.

9. Smith-Bindman R, Lipson J, Marcus R, Kim KP, Mahesh M, Gould R, Berrington de González A, Miglioretti DL. Radiation dose associated with common computed tomography examinations and the associated lifetime attributable risk of cancer. Arch Intern Med. 2009 Dec 14;169(22):2078-86. doi: 10.1001/archinternmed.2009.427.

10. Dubé BP, Dres M. Diaphragm Dysfunction: Diagnostic Approaches and Management Strategies. J Clin Med. 2016 Dec 5;5(12):113. doi: 10.3390/jcm5120113.

11. Kansal AP, Chopra V, Chahal AS, Grover CS, Singh H, Kansal S. Right-sided diaphragmatic eventration: A rare entity. Lung India. 2009 Apr;26(2):48-50. doi: 10.4103/09702113.48898.

12. Kokatnur L, Rudrappa M. Diaphragmatic Palsy. Diseases. 2018 Feb 13;6(1):16. doi: 10.3390/diseases6010016.

13. SALIH HAA. Measurement of the height difference between right and left hemi diaphragm in normal Sudanese

*Corresponding author: Dr. S Alghamdi, PhD. Department of Applied Radiologic Technology, College of Applied Medical Sciences, University of Jeddah, Jeddah, Saudi Arabia.E-mail: ssalghamdi85@ gmail.com 
adult using posteroanterior chest radiograph. Sudan University of Science and Ttechnology; 2013.

14. Klein JS, Rosado-de-Christenson ML. A Systematic Approach to Chest Radiographic Analysis. 2019 Feb 20. In: Hodler J, Kubik-Huch RA, von Schulthess GK, editors. Diseases of the Chest, Breast, Heart and Vessels 2019-2022: Diagnostic and Interventional Imaging [Internet]. Cham $(\mathrm{CH})$ : Springer; 2019. Chapter 1. PMID: 32096946.

15. Suwatanapongched T, Gierada DS, Slone RM, Pilgram TK, Tuteur PG. Variation in diaphragm position and shape in adults with normal pulmonary function. Chest. 2003 Jun;123(6):2019-27. doi: 10.1378/chest.123.6.2019.

16. Brant WE, Helms CA. Diagnostic imaging methods.
Fundamentals of Diagnostic Radiology. 2nd ed Philadelphia (PA). Lippincott Williams and Wilkins; 1999.

17. Chetta A, Rehman AK, Moxham J, Carr DH, Polkey MI. Chest radiography cannot predict diaphragm function. Respir Med. 2005 Jan;99(1):39-44. doi: 10.1016/j.rmed.2004.04.016. 18. Kazerooni EA. High-resolution CT of the lungs. AJR Am J Roentgenol. 2001 Sep;177(3):501-19. doi: 10.2214/ ajr.177.3.1770501.

19. Kalra MK, Maher MM, Rizzo S, Kanarek D, Shepard JA. Radiation exposure from chest CT: issues and strategies. J Korean Med Sci. 2004 Apr;19(2):159-66. doi: 10.3346/ jkms.2004.19.2.159. Erratum in: J Korean Med Sci. 2004 Jun;19(3):487. Shephard JA [corrected to Shepard JA]. 